\title{
DIVERSIDADE CULTURAL, ALTERIDADE E VIDA: O CINEMA PARA PENSAR ATOS DE CURRÍCULO NOS ESPAÇOSTEMPOS DE APRENDIZAGEM
}

\author{
DIVERSIDAD CULTURAL, ALTERIDAD Y VIDA: EL CINE PARA PENSAR ACTOS \\ CURRICULARES EN LOS ESPACIOS DE APRENDIZAJE
}

\section{CULTURAL DIVERSITY, ALTERITY AND LIFE: CINEMA TO THINK CURRICULAR ACTS IN LEARNING SPACES}

\author{
Mirian AMARAL ${ }^{1}$ \\ Tania Lucía MADDALENA ${ }^{2}$ \\ Edméa SANTOS ${ }^{3}$
}

RESUMO: Na contemporaneidade, o digital em rede vem alterando, cada vez mais, processos de comunicação, de sociabilidade, de educação e aprendizagem, convidando-nos a pensar de que forma o cinema, como objeto sociocultural e dispositivo de aprendizagem, pode possibilitar momentos de reflexão, análise e criação. Alinhadas à abordagem dos cotidianos escolares (CERTEAU, 2013; ALVES, 2008) e aos princípios da pesquisaformação multirreferencial (SANTOS, 2014), neste artigo, as autoras, à luz do filme argentino "Um conto chinês", criam atos de currículo, favorecendo práticas pedagógicas que relacionam o conhecimento científico ao conhecimento comum, e contemplam a diversidade cultural, o diálogo e a alteridade. Assim, e dando oportunidade para desenvolver novas visões do mundo, entrelaçam arte e educação em uma pesquisa-formação realizada no âmbito da disciplina "Cotidianos e currículos", no Curso de Graduação em Educação da Universidade do Estado do Rio de Janeiro - UERJ, durante o curso de doutorado, de 2015-16, que contou com 34 estudantes. Como resultado dessa experiência, obtêm diferentes narrativas de futuros professores que mostram o poder do cinema para pensar o cotidiano escolar.

PALAVRAS-CHAVE: Cinema. Atos de currículo. Diversidade cultural. Alteridade.

RESUMEN: En la contemporáneidad, la tecnología digital viene alterando cada vez más los procesos de comunicación, de sociabilidad, de educación y aprendizaje, invitándonos a pensar cómo el cine, como objeto sociocultural y dispositivo de aprendizaje, puede posibilitar momentos de reflexión, de análisis y de creación. En línea con el enfoque de la vida escolar cotidiana (CERTEAU, 2013; ALVES, 2008) y los principios de la formacióninvestigación multirreferencial (SANTOS, 2014), los autores, a la luz de la película argentina "Un cuento chino", crean actos curriculares, favoreciendo prácticas pedagógicas

\footnotetext{
${ }^{1}$ Fundação Getúlio Vargas (FGV), Rio de Janeiro - RJ - Brasil. Professora dos cursos MBA do programa FGV Mangement/FGV. Doutora em Educação pela Universidade Estácio de Sá (UNESA). ORCID: https://orcid.org/0000-0002-9472-7571. E-mail: amaral3378@gmail.com

${ }^{2}$ Universidade Internacional de La Rioja (UNIR), Alicante - España. Professora do Mestrado em Formação de Professores de Ensino Médio, Formação Profissional e Ensino de Línguas. Doutorado em Educação (Proped/UERJ). ORCID: https://orcid.org/0000-0002-3949-6491. E-mail: tlmaddalena@ gmail.com

${ }^{3}$ Universidade Federal Rural do Rio de Janeiro (UFRRJ), Rio de Janeiro - Brasil. Professora titular livre do programa de pós-graduação em Educação. Doutora em Educação pela Universidade Federal da Bahia (UFBa). ORCID: https://orcid.org/0000-0003-4978-9818. E-mail: edmeabaiana@gmail.com
}

RIAEE - Revista Ibero-Americana de Estudos em Educação, Araraquara, v. 15, n. 2, p. 650-666, abr/jun. 2020. e-ISSN: 1982-5587. 
que relacionan el conocimiento científico con el conocimiento común y contemplan la diversidad cultural, el diálogo y la alteridad. Así, y dando oportunidad al desarrollo de nuevas visiones de mundo, entrelazan arte y educación en una investigación-formación realizada en el ámbito de la disciplina en línea "Cotidianos y Currículos", en el grado en Educación de la Universidad del Estado de Río de Janeiro - UERJ, durante el curso de doctorado en el año 2015 y 2016, que tuvo 34 estudiantes.. Como resultado de esta experiencia, se obtuvieron diferentes narraciones de futuros profesores que muestran el poder del cine para pensar el cotidiano escolar.

PALABRAS CLAVE: Cine. Actos curriculares. Diversidad cultural. Alteridad.

ABSTRACT: In the contemporaneity, the digital network has been changing, increasingly, processes of communication, sociability, education and learning, inviting us to think about how cinema, as a sociocultural object and as a learning device, can enable moments of reflection, analysis and creation. In line with the approach to everyday school life (CERTEAU, 2013; ALVES, 2008) and the principles of multi-referential training-research (Santos, 2014), the authors, in the light of the argentine film "A Chinese Tale," create curricular acts, which are based on the approach to school daily life (CERTEAU, 2013, ALVES, 2008) and the principles of research -multireferential training (SANTOS, 2014), favoring pedagogical practices that relate scientific knowledge to common knowledge, and contemplate cultural diversity, dialogue and otherness.. Thus, and giving opportunity to the development of new worldviews, they interweave art and education in a research-training carried out in the field of the online discipline "Cotidianos y Currículos", in the Graduation Course in Education of the University of State of Rio de Janeiro - UERJ, during the doctoral course, in the period of 2015-2016, que tuvo 34 estudiantes. As a result of this experience, they obtain different narratives from future teachers that show the power of the cinema to think about the daily school.

KEYWORDS: Cinema. Curricular acts. Cultural diversity. Otherness.

\section{Introdução}

A emergência das tecnologias digitais em rede, responsáveis pelas transformações dos processos de comunicação, sociabilidade, educação e aprendizagem, convida-nos a pensar sobre a relação entre educação e artes, principalmente no que diz respeito às projeções de filmes como dispositivos que favorecem a criação de currículos que possibilitam o desenvolvimento de processos reflexivos e críticos.

Se, como afirma Fresquet (2013, p. 9), a arte atravessa as certezas da educação, provocando-a, constituindo-se como um 'outro' em relação a nós, professores e alunos, “espelhando-nos com seu olhar, devolvendo nossa própria imagem com outras cores e formas. [...] também se revela como uma janela para descobrir um mundo inacabado, ávido de transformações e memórias para projetar futuros" (p. 9).

RIAEE - Revista Ibero-Americana de Estudos em Educação, Araraquara, v. 15, n. 2, p. 650-666, abr./jun. 2020. e-ISSN: 1982-5587. 
As experiências e processos criativos se aproximam e se potencializam quando criamos espaços de diálogo entre educação e arte, superando os limites estabelecidos pelas explicações, manifestando outras dimensões que produzem conhecimento a partir do arrebatamento, do arrepio, da falta de domínio de si, sem estrutura lógica. Nessa perspectiva, a cultura é matéria-prima no processo de significação e no imbricamento de experiências intelectuais e sensíveis. As produções que emergem dessas experiências podem registrar modos de ser e viver na contemporaneidade, retratar culturas locais, compartilhar conhecimentos diversos e abordar questões sociopolíticas - aspectos que podem ser explorados por um currículo que dialogue com a vida cotidiana e com as subjetividades dos indivíduos, que vão para além da perspectiva da rede curricular (ALVES; NEVES; PAZ, 2014)

Não há dúvida de que a natureza homogeneizadora que caracteriza os currículos oficiais acaba 'silenciando' aquelas subjetividades que não se alinham às normas preestabelecidas pelas instituições de ensino, dificultando o surgimento de novos conhecimentos e novas relações entre os sujeitos; o que vai ao encontro do pensamento de Xavier e Canen (2008), que afirmam que as instituições educacionais devem ser repensadas como loci culturais, que revelam e combatem processos exclusivos, promovem reflexões sobre a relação entre cultura e poder, desenvolvem ideias em torno de cidadania crítica e o respeito à diversidade, às diferenças e à multiplicidade. Desse modo, é relevante, no processo formativo de professores, a incorporação de uma visão multicultural que possa ser traduzida em suas práticas pedagógicas, nos currículos "pensadospraticados", entendidos como processos discursivos, impregnados de relações desiguais de poder que participam da formação de identidades.

Fresquet (2013) afirma que, ao se levar a arte para espaços educativos, imprime-se uma grande responsabilidade na reinvenção de si mesmo e do mundo com o outro, numa relação de alteridade, na medida em que se trata de construir textos que dialoguem e toquem a vida de alguma maneira; que se façam vida, ao se deixarem "conduzir por um ritmo, manter-se em silêncio, deslizar-se na oscilação dos tons, modular-se em uma melodia" (LARROSA, 2012, p. 9), para que as palavras estimulem a reflexão e surpreendam, em uma frase, em um pensamento.

Para Bergala (2008), o aprendizado é mediado pelo desejo, pois não é possível aprender a desejar sem ser afetado; o que exige iniciativas como: (a) implementação de estratégias que permitam o encontro dos estudantes com filmes, seja com a criação de acervos, no contexto escolar, seja por meio de visitas a cinematecas e salas alternativas de 
cinema; (b) mudança do status simbólico do educador - de detentor do conhecimento para o do parceiro, coautor do processo educativo; e (c) a criação de condições para o desenvolvimento da reflexão e da crítica, e a emergência da criatividade.

Com efeito, no contexto das mídias educativas, o cinema pode ser entendido sob as perspectivas estéticas, cognitivas, sociais e psicológicas, contribuindo para pensar a escola como um espaço no qual é sempre possível inovar. No entanto, não basta abordá-lo na perspectiva instrumental, como uma simples fonte de informação e meio de realização de pesquisas. É preciso ir além: explorar todo o seu potencial e integrá-lo às práticas pedagógicas que acentuam o caráter dialógico, interativo, colaborativo e autoral do processo educativo (AMARAL; BOHADANA, 2008).

Este artigo é um subproduto de uma pesquisa, realizada no curso de Doutorado em Educação da Universidade do Estado do Rio de Janeiro, durante no período de 2015 e 2016. Seu objetivo central é discutir como o cinema, objeto sociocultural e dispositivo de aprendizagem pode proporcionar momentos de reflexão, análise e criação, a partir da experiência vivida na disciplina online "Cotidianos e currículos", oferecida a 34 alunos da graduação em Educação.

Nessa disciplina, desenvolvida no formato híbrido de ensino, as autoras objetivaram, por meio de processos de auto, hetero e ecoformação, compreender o significado dos cotidianos nas redes de conhecimentos e significações nas quais nos inserimos, bem como a expressão dessas redes nessas ambiências, com ênfase nas relações "dentrofora" das escolas, nos processos de "aprendizagemensino", nos múltiplos artefatos culturais usados e nos "fazeressaberes", "docentesdiscentes" curriculares.

Desse modo, junto com os praticantes culturais, coautores dessa pesquisa, e a partir do filme "Um Conto Chinês" (Anexo 1), criamos atos de currículo para favorecer o desenvolvimento de práticas pedagógicas participativas, que consideraram tanto os saberes científicos como os saberes comuns presentes nos cotidianos, na cultura, nas mídias e nas tecnologias, e o respeito à realidade brasileira de diversidade e pluralidade cultural, com vistas a acentuar o caráter dialógico, interativo, colaborativo e autoral do processo educacional.

\section{O mundo é uma aldeia multicultural?}

Hoje, para além do lugar, das cidades e do país, reina o ciberespaço, repleto de técnicas, conhecimentos, práticas, pensamentos, atitudes, crenças e valores, que 
desterritorializa e ocupa o imaginário coletivo, dando origem a novos estilos, visões e sentimentos, que afetam o cotidiano de cada indivíduo. Em tempos de mobilidade ubíqua, cada vez mais grupos de diferentes culturas se aproximam e, como preconizou McLuhan (1964), modelam uma aldeia global - e por que não dizer, uma aldeia multicultural?

De fato, embora a sociedade esteja repleta de desigualdade e discriminação entre as pessoas, um dos princípios mais importantes do direito é o da igualdade perante a lei, devendo cada um preservar e garantir esse princípio em suas relações e em sua própria vida em sociedade, deixando as diferenças por conta dos costumes, hábitos e valores, que coabitam com outros valores, muitas vezes de maneira conflitante. Assim, reconhecer e respeitar a diversidade cultural constitui o primeiro passo para a convivência harmônica, não apenas na perspectiva jurídica, mas também sob o ponto de vista humano e social.

Bakhtin (2011) entende o sujeito como um conjunto de relações sócio-históricas. Nessa perspectiva, a linguagem é vista como um fenômeno social. Consequentemente, seus signos são variáveis e flexíveis; o que lhe confere um caráter mutável, histórico e polissêmico, não podendo, em seu uso prático, ser entendida e explicada fora desse elo. Para o autor, a língua está em constante evolução, como resultado das interações verbais entre os interlocutores. É em seu contato com a realidade concreta, via enunciado, que a palavra ganha sentido, dado que este se revela em sua profundidade quando encontra e toca outro sentido, estabelecendo um diálogo entre eles que supera a natureza fechada e inequívoca da obra.

Para Sennett (apud BAUMAN, 2001, p. 111), uma cidade é "um assentamento humano no qual estranhos têm a oportunidade de se encontrar na condição de estranhos, terminando o encontro de maneira tão abrupta como a que o ocasionou".

Se, como ressalta Bauman (2001), a proximidade física não pode ser evitada, pode pelo menos remover a ameaça de 'estar juntos', deixando de lado o diálogo e a interação. No entanto, a essência da natureza humana é definida pela alteridade, na medida em que a presença do outro é fundamental para sua concepção (BAKHTIN, 2011). Assim, torna-se necessário o entendimento de que somos o produto da interação com o outro que, em última análise, constitui uma parte ativa na construção de nossa identidade. "Os sujeitos se constituem por meio do(s) outro(s), dialogicamente, numa interatividade complexa e dinâmica, com orientações ideológicas próprias”, afirma Osório (2008, p. 60).

Em uma sociedade como a nossa, cuja pluralidade de culturas, religiões, visões de mundo, etnias e outras dimensões das identidades se infiltram, exponencialmente, o multiculturalismo surge como um conceito que nos permite, mediante a criação de atos de 
currículo, questionar a 'superioridade' do conhecimento, geral e universal, sobre o conhecimento particular e local.

\section{Pesquisa-formação multirreferencial na cibercultura ${ }^{4}$}

Durante a segunda metade do século XX, aumentou o interesse em associar a pesquisa com experiências de formação. Nessa época, emerge na área da educação uma série de métodos de pesquisa que incentivam a intervenção direta no campo da pesquisa, uma intervenção projetada e articulada com os sujeitos da pesquisa. A partir dessas práticas, são esperadas fecundas transformações, decorrentes de reflexões e análises futuras. Entre esses métodos encontra-se a pesquisa-ação (THIOLLENT, 1986; BARBIER, 2007, entre outros), que valoriza o potencial que a pesquisa educacional pode assumir, enfatizando uma visão ampla e comprometida da realidade.

Para a realização de nosso estudo, adotamos os pressupostos da pesquisa com os cotidianos (ALVES, 2008; CERTEAU, 2013), um ponto-chave para pensar os sujeitos imersos em suas práticas educativas. Utilizamos a noção de praticante cultural ${ }^{5}$, entendendo os sujeitos como atores e 'praticantes' de seus cotidianos, valorizando as práticas, criações e operações diárias do homem comum. Assim, cada praticante cultural chega ao nosso encontro trazendo conhecimentos, desejos e preocupações gerados em outras redes e espaços educativos. Assim, todos os repertórios, histórias de vida e trajetórias de formação de cada aluno entram em cena na realização da prática pedagógica.

A essa perspectiva acrescentamos os princípios da pesquisa-formação multirreferencial na cibercultura (ARDOINO, 1998; MACEDO, 2012; SANTOS, 2014), que encontra na pesquisa-ação algumas de suas referências, e é um modo filosófico de existir e fazer pesquisa interdisciplinar para um pesquisador comprometido com sua prática. Autores como Nóvoa (2004), Macedo (2012), Josso (2004) trazem sustentação teórica para compreender o sujeito em formação e a tarefa do professor que, nesse método, é entendido, ao mesmo tempo, como objeto e sujeito em formação. Por isso, é importante pensar na prática de ensino para além da racionalidade técnica, e como uma fonte de conhecimentos; um lugar privilegiado para realizar uma pesquisa.

${ }^{4}$ Cultura contemporânea, móvel e ubíqua, permeada pelas tecnologias digitais em rede.

5 "Praticante cultural", termo concebido por Certeau (2013), referente aqueles que vivem e se relacionam dialogicamente com as práticas cotidianas. Para o autor, quando o homem comum se torna narrador, quando define o lugar (comum) do discurso e o espaço (anônimo) de seu desenvolvimento, a abordagem da cultura tem sua origem. Sob esse ponto de vista, espaços e tempos de criação coletiva e ação política emergem como componentes fundamentais no processo de transformação da escola. 
A ideia de conceber a prática de ensino como uma prática de pesquisa possibilita a experiências formativas na cibercultura e potencializa autorias-cidadãs, na medida em que o professor-pesquisador, além da intencionalidade de formar o outro, forma a si mesmo, por meio de um processo de reflexão sobre suas itinerâncias pessoais e profissionais autoformação; forma-se no relacionamento com os outros - heteroformação; e, por intermédio das coisas - conhecimento, técnicas, culturas, artes, tecnologias, entre outras, e de sua compreensão crítica - ecoformação (PONCE PINEAU, 1988).

Implica, portanto, uma intervenção participativa na realidade social investigada, tornando tênue a fronteira pesquisador/pesquisado, ao desenvolver a dialética da ação em um processo coletivo e único, com base nos princípios do compromisso do pesquisador com suas práticas, na construção do conhecimento.

De fato, a pesquisa-formação busca movimentos de transformação individuais e coletivos, baseados em experiências formativas a partir de uma abordagem dialética entre prática, teoria e prática. Assume, dessa forma, a complexidade da realidade, pondo em evidência as práticas sociais que surgem em diferentes contextos, porque, diferentemente da escolaridade, que ocorre em ambientes fechados, nessa modalidade a aprendizagem vai muito além dos muros da escola e da universidade, relacionando, de forma híbrida, os "espaçostempos" que nos cercam, criando, como enfatiza Santaella (2010), espaços intersticiais na conjugação do ciberespaço com as cidades.

Coerentes com seus princípios, que concebem o currículo como um trabalho criativo, marcado pela flexibilidade e dinamismo, adentramos os cotidianos escolares, trazendo premissas, como: (a) práticas educativas baseadas na reprodução e memorização, em geral, negam ao aluno o direito à criação e não favorecem o desenvolvimento de outros processos; (b) a apropriação das tecnologias digitais como reprodutoras de práticas não promove processos interativos, dialógicos e colaborativos, inibindo a manifestação da autoria, sob diferentes formas de expressão; e (c) a prática da escrita criativa deve ser estimulada, incentivada e materializada em suportes duráveis, que possibilitem o livre acesso, a reutilização e a remixagem.

Como sujeitos comprometidos com o campo, tratamos, ao mesmo tempo, de romper com a dicotomia entre os pares presencial/online, ensino/pesquisa, aprender/ensinar, dentro /fora, entre outros, num esforço para integrar temas inerentes a nossa disciplina e interagir com os praticantes no desenvolvimento de nossa pesquisa, expectativa de obtenção de dados relevantes para o desenvolvimento de nossa pesquisa. 
Além da preocupação e intencionalidade com a formação dos profissionais, criamos situações significativas de aprendizagem (atos de currículo) que impulsionaram o surgimento da autoria. $\mathrm{O}$ uso intensivo de diferentes dispositivos materiais e intelectuais possibilitou o surgimento de conversas, debates e narrativas diversas, apresentadas de forma oral, textual e por meio de imagens. Assim, nosso objetivo era trazer uma narrativa cinematográfica para discutir, com os participantes, aspectos culturais, históricos, literários e políticos inerentes a ela, permitindo o desenvolvimento de novas visões de mundo, à luz da realidade dos praticantes. Nessa perspectiva, utilizamos, inicialmente, um dos encontros presenciais para exibição do filme "Um Conto Chinês", cuja ficha técnica e sinopse são apresentadas, a seguir.

\section{Resultados}

A partir deste filme, juntamente com os praticantes, criamos situações significativas de aprendizagem (atos de currículo), incentivando-os a compartilharem conhecimentos, práticas, valores, representações e emoções, objetivando não apenas despertar-lhes o sentimento de pertencimento a um grupo, mas que pudessem desenvolver o senso de colaboração, buscando valorizar as singularidades, numa perspectiva crítico-reflexiva.

Organizados em círculo, trouxemos informações sobre a temática, a equipe técnica, a filmagem, entre outras, que contribuíssem para melhor compreensão do tema, da trama, da linguagem e do lugar daquele filme no contexto da história do cinema, em nível nacional e mundial. Falamos, também, sobre a experiência vivenciada, considerando a forma como o filme os tocou.

Em geral, os participantes gostaram muito do filme. Ressaltaram que, apesar de sua pegada mais próxima da comédia, apresentava uma boa dose de humor negro, mas também os fazia pensar sobre as questões relacionadas com a diversidade cultural, presente na realidade brasileira. Elogiaram o roteiro e a direção de Borensztein, por ter optado por uma linguagem comum, desprovida de formalismos, e colocar seu foco no personagem Roberto, trazendo para o cotidiano de sua vida um pouco de exagero.

Praticante Laís S. - O roteiro é simples, com uma pitada de ironia. Há muito de comédia; mas há espaço para a reflexão e a emoção. A gente fica pensando sobre o motivo das coisas, se existe acaso, sobre o sentido da amizade [...]. Gostei muito da cena em que Roberto, cujo hobby é colecionar notícias incriveis e absurdas, descobre, perplexo, a verdadeira história de Jun, e exclama: "Deus, meu! Essa notícia era sobre ele? Essa era sua noiva? Não pode ser!”. 
Praticante Monique C. - Destaco o papel que o outro exerce em nossas vidas; a importância do diálogo e da interação entre os sujeitos, em suas constituições. Fiquei pensando sobre como nós brasileiros podemos contribuir para modificar a prática étnico-racial que existe em nossa sociedade, e a necessidade de trabalharmos com nossos alunos questões como aceitação da diversidade, das diferenças, das desigualdades, entre outros aspectos.

Dado o interesse dos alunos em relação à atividade cineclubista, decidimos ampliar as discussões sobre diversidade e pluralidade cultural "dentrofora" da escola. Para isso, usamos a interface do fórum de conversas, no Ambiente Virtual de Aprendizagem (AVA), de nosso curso, na plataforma Moodle.

Propusemos aos participantes que procurassem, no cinema, narrativas que apresentassem atos curriculares sobre esses temas, no Brasil e no exterior, levando em conta que, para o cotidiano escolar, o lugar da rotina também é um lugar de invenções; o que mais interessa são as operações de seus usuários (CERTEAU, 2013), práticas inovadoras. Assim, organizamos as atividades da seguinte forma:

- Escolha um filme para revisar;

- Apresente uma resenha crítica (duas páginas) que dialogue com os conceitos e noções de 'currículos' e 'cotidianos', já trabalhados, e possa ampliar outras discussões;

- Escolha uma resenha crítica de filme, enviada por um parceiro, e faça um comentário;

- Todos devem participar do fórum "Os cotidianos escolares no cinema".

Para aproximar o conhecimento científico e o senso comum e, assim, dar mais sustentabilidade ao trabalho proposto, sugerimos a leitura de dois artigos: Santos e Okada (2003) e Santos (2010).

A resenha crítica do filme "Entre os Muros da Escola", apresentada a seguir, e elaborada pela praticante Thaís B., a exemplo de "Um Conto Chinês", aborda o tema do multiculturalismo, de grande atualidade e pertinência, fazendo-nos refletir sobre a problemática da diversidade cultural, as consequências advindas da interação dessas culturas, os desafios que se colocam aos professores, e as estratégias de que lançam mão em suas práticas educativas. 


\section{Reseña de la Película 'La Clase'}

\section{Sinopse}

Um professor tenta estimular seus alunos na sala de aula, mas enfrenta problemas com a falta de educação e o cansaço desinteresse dos estudantes por aprender alguma coisa.

\section{Ficha Técnica}

Título Original: Entre les Murs.

Origen: França, 2008.

Dirección: Laurent Cantet.

Guión: Laurent Cantet, François Bégaudeau e Robin Campillo, baseado no livro de François Bégaudeau Atores: François Bégaudeau, Nassim Amrabt, Laura Baquela, Cherif Bounaïdja Rachedi, Juliette Demaille, Dalla Doucoure, Arthur Fogel e Damien Gomes

Web oficial: http:// www.entrelesmurs.ca

O filme "Entre os muros da escola" apresenta um contexto social caracterizado pelo choque cultural existente entre os indivíduos de uma escola localizada na periferia de Paris. A história se passa com alunos adolescentes na faixa etária dos 13 a 15 anos, oriundos de diferentes etnias, como asiáticos, chineses, latinos e afrodescendentes, todos predominantes das classes populares. Com tanta diferença cultural e social, os conflitos nas relações cotidianas tornam-se constantes.

Os problemas sociais vivenciados por esses alunos são refletidos diretamente na escola. Podemos destacar, por exemplo: a deportação da mãe de um aluno chinês, chamado Wei, e o caso do aluno Souleymane, definido pelos professores como "problemático", com um histórico de agressões verbais e físicas aos docentes e a outros alunos. Por conta disso, o referido aluno é citado no conselho de classe para que seja alcançada uma medida punitiva para seu comportamento inadequado. No entanto, os educadores deparam-se com um obstáculo social: a expulsão do aluno resultará no seu retorno ao país de origem.

Essas divergências culturais, em dados momentos acarretam dificuldades de comunicação entre escola e família. Fato ocorrido com o já citado Souleymane, que tem como seu responsável sua mãe, que somente se comunica através de seu dialeto de origem. Nesse contexto fica muito difícil manter a qualidade do ensino. Portanto, podemos notar que o contexto social está intimamente ligado ao cotidiano escolar, interferindo no processo de ensino-aprendizagem das escolas. Por conta disso, deve-se não menosprezar, e sim, fazer uso do contexto social de modo que colabore positivamente com a dinâmica escolar.

Em relação ao contexto escolar, trata-se de uma escola pública e tradicional da periferia de Paris, a qual volta-se para alunos filhos de imigrantes, majoritariamente pobres, e visa educar para sua incorporação à cultura francesa. Além dos conteúdos curriculares básicos, a escola tenta passar àqueles diferentes sujeitos o "modo correto de falar e se comportar naquele país". É como se fosse um processo civilizatório, o qual ignora a cultura de cada indivíduo e introduz naqueles imigrantes a cultura local.

Em meio a essa situação, encontramos defasadas metodologias pedagógicas, com aulas expositivas e sem muitos recursos. Os professores durante os conselhos de classe não chegam a um consenso quanto às metodologias de ensino-aprendizagem, de valorização do estudante ou de práticas de advertências. Impacientes, perdidos diante das atitudes dos alunos, não sabem como conciliar as punições e o contexto social dos alunos que, estressados, agem com desrespeito, apresentando baixo rendimento, falta de atenção e pouca participação durante as aulas, sempre questionando a autoridade do professor. Por conta disso, a rotina caracteriza-se pela falta de interesse, desrespeito, insultos, violências de ambas as partes (educadores e alunos); enfim, conflitos oriundos de diversas razões. 
Em continuidade à resenha do filme selecionado, a praticante cultural apresentou comentários adicionais, num movimento de aproximação das temáticas que emergiram ao longo da película à realidade do cotidiano e do currículo escolar.

O filme retrata um cotidiano escolar muito complicado, permeado de brigas, conflitos, diversidade, intolerância e desrespeito. Esse cotidiano não nos é estranho, dado que diferenças sociais, culturais e étnicas, pensamentos e valores diferenciados estão presentes em nossas escolas, $e$ constituem um desafio permanente para educadores, que devem refletir sobre suas práticas pedagógicas, a fim de minimizar ou evitar os conflitos emergentes. $O$ que não pode ocorrer é o professor utilizar de sua autoridade para minimizar e discriminar seus alunos. Por isso, acho que devemos ficar atentos não só às questões das relações sociais, mas também aos aspectos que envolvem o processo ensino aprendizagem. Isso me faz pensar e questionar sobre qual currículo perpassa esse cenário? que intencionalidade e relações de poder são intrínsecas a ele? será que o currículo oficial consegue ser posto em prática nesse contexto? será que o currículo oficial está condizente com o currículo oculto?

Penso, que a partir de um currículo formal, principalmente nas disciplinas de história, literatura, artes e até ensino religioso, seja possivel trabalhar questões como diversidade cultural, respeito e tolerância. Os próprios conteúdos inerentes a essas áreas podem ser ampliados, buscandose uma perspectiva mais crítica e reflexiva. [...] Temas como indígenas (ex.: catequização) e afrodescendentes (ex.: escravidão) podem ser explorados para além do fato histórico, onde identificamos o grupo dominante e o dominado. Não só os transmitir, ou apresentá-los "de forma superficial", mas sim trabalhar os conteúdos, comparando-os, trazendo outros elementos $e$ identificando as relações sociais existentes neles.

Para mim, essa prática não deve ser direcionada a um público específico, restrito e limitado; pelo ao contrário, deve estar presente em todas as séries, desde os anos iniciais do ensino fundamental; claro, respeitando as características dos discentes e estando de acordo com o grau de complexidade dos conteúdos. Além disso, indico um textol que apresenta uma discussão interessante sobre autoridade e autoritarismo, pois acredito que esses aspectos estão presentes no nosso cotidiano escolar e interferem diretamente nas nossas relações pedagógicas.

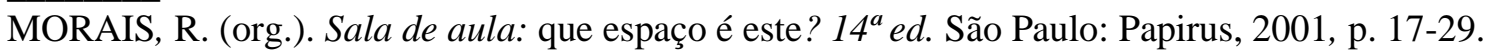

Como observamos a escola como um espaço legítimo no qual o processo de socialização ocorre e onde, inexoravelmente, a convivência multicultural se impõe, ela constitui o ambiente propício à discussão sobre diversidade - cultural, racial, social, entre outras. Isso implica a capacidade de se colocar no lugar do outro, num relacionamento baseado no diálogo e na valoração das diferenças existentes.

Para Bakhtin (2011), a interação ocorre por meio da linguagem, num contexto em que todos participam de forma igual. Quem enuncia seleciona palavras apropriadas para formular uma mensagem que possa ser compreendida pelos destinatários. Por outro lado, o interlocutor interpreta e responde ativamente a essa afirmação. Essa compreensão responsiva pelo autor implica posicionar-se, fornecendo uma resposta à resposta localizada no contexto do movimento interlocutivo. 
Desse modo, é natural que, diante de uma nova língua, de uma nova cultura, haja, em princípio, certo estranhamento. Mas é necessário entender e conviver com o que é diferente, com o que não nos é familiar, pois o conhecimento de nossa cultura pressupõe o conhecimento de outras culturas, reconhecendo que somos uma cultura entre muitas outras, mas não a única. Todas as "[...] palavras são tecidas a partir de uma infinidade de linhas ideológicas e servem de trama a todas as relações sociais em todos os domínios" das atividades humanas, enfatiza Bakhtin/Voloshinov (2009, p. 42). Assim, estão diretamente ligadas à vida e, por excelência, são atravessadas pelo discurso que constitui o cenário de um determinado evento. Nesse sentido, a prática educativa consiste em um evento discursivo, que evidencia sua estruturação/organização, a partir de simples afirmações que visam facilitar o diálogo entre sujeitos sócio-históricos.

Finalmente, nosso papel como mediadores foi o de propor desafios, criar situações problemáticas e intervir nas discussões, instigando os praticantes a buscarem a compreensão dos conceitos desenvolvidos, iniciando a (re)construção de seus conhecimentos, de forma autoral, além de favorecer o surgimento de outras mediações. Ao expressarem suas opiniões por escrito, os praticantes expuseram seus pensamentos, firmaram um compromisso com a verdade que produziram - um ato responsivo, como enfatiza Bakhtin (2011), além de demarcar um local de alteridade, possibilitando assim o estabelecimento de uma relação dialógica, na qual a crítica, os confrontos ideológicos e o discurso polifônico se instituem. Como vimos, mediante o uso de tecnologias de rede digital, foi possível gerar atos de currículo, aprimorando o processo de aprendizagem.

\section{Conclusão}

Como a linguagem escrita nos permite conhecer o mundo e nossa cultura, de maneira sistemática e conceitual, imagens estáticas ou em movimento constituem as narrativas do mundo contemporâneo e nos fornecem novos elementos para entender o próprio conceito de narrativa. Assim, as práticas pedagógicas podem ser analisadas por meio de suas representações em imagens ou descrições verbais ou, até, na articulação de ambas as linguagens.

Neste artigo, apresentamos como pano de fundo o filme "Um Conto Chinês". Criamos atos curriculares que favoreceram práticas pedagógicas que relacionam o conhecimento científico ao conhecimento comum, contemplando a diversidade cultural, o diálogo e a 
alteridade, presentes em nossos cotidianos escolares, como pudemos vivenciar, no âmbito da pesquisa que realizamos.

Como uma experiência única de um ser em aprendizagem, a formação surgiu a partir de modelos propositivos e explicativos engendrados por meio de atos de currículo que estimularam a cooperação, a tessitura do conhecimento, de forma coletiva, a participação em debates e o desenvolvimento da autonomia e de autorias diversas.

Ao abordarmos essas questões, com base em narrativas cinematográficas, nosso objetivo era articular mídia e educação, utilizando o cinema para aprimorar currículos multirreferenciais, baseados em processos de "aprendizagemensino" que implicam o desenvolvimento da reflexão e da capacidade crítica e criativa, a partir da articulação e experiência do conhecimento em uma perspectiva de pluralidade; o que exige priorizar as relações, a heterogeneidade, o diálogo, a alteridade, entre outras.

\section{REFERÊNCIAS}

ALVES, N. Decifrando o pergaminho: os cotidianos das escolas nas lógicas das redes cotidianas. In: Oliveira, Inês. B.; Alves, Nilda (Orgs.). Pesquisa nos/dos/com os cotidianos das escolas. Petrópolis: DP et Alii, 2008, p. 15-38.

ALVES, L. R. G.; NEVES, B. N.; PAZ, T. S. Constituição do currículo multireferencial na cultura da mobilidade. Revista de currículo eletrônico. São Paulo, v. 2, n. 12, maio/out. 2014 Disponível em: http://revistas.pucsp.br/index.php/curriculum. Acesso em: 15 maio 2018 .

AMARAL, M. M.; BOHADANA, E. Conectividade e mobilidade social: pilares da inclusão digital? Contemporânea, v. 6, n. 2, p. 1-21, dez. 2008.

ARDOÍNO, J. Pesquisa multireferencial (plural) de situações de ensino e treinamento. In: Barbosa, Joaquim. G. (coord.) Multireferencialidade em ciências sociais e educação. São Carlos: UFScar, 1998.

BAKHTIN, M. Estética da criação verbal. São Paulo: Martins Fontes, 2011.

BAUMAN, Z. Modernidade líquida. Trad. Plínio Dentzien. Rio de Janeiro: Zahar, 2001.

BERGALA, A. A hipótese-cinema: pequeno tratado de transmissão do cinema dentro e fora da escola. Rio de Janeiro: Booklink e CINEAD/UFRJ, 2008.

CERTEAU, M. A invenção do cotidiano: artes de fazer. Petrópolis: Vozes, 2013.

FRESQUET, A. Cinema e educação: reflexões e experiências com professores e estudantes de educação básica, dentro e "fora" da escola. Belo Horizonte: Autêntica (Coleção Alteridade e Criação), 2013. 
JOSSO, M. C. Experiências de vida e treinamento. São Paulo: Cortez, 2004.

LARROSA, J. Prologue: uma experiência sensível com a linguagem. In: Kliar, C.

Experiências com a palavra: notas sobre linguagem e diferença. Rio de Janeiro: Wak, 2012.

MACEDO, R. S. Critical Ethnoresearch e Ethnoresearch-training. Brasília: Liberlivro, 2006.

MACEDO, R. S. C. Multirreferencialidade: o pensar de Jacques Ardoino em perspectiva e a problemática da formação. In: Macedo, R. S. C.; Barbosa, J. G.; Borba, S. (Orgs). Jacques Ardoino \& a educação. Belo Horizonte: Autêntica (Coleção Pensadores @ Educação), 2012. Disponível em: https://formacce.ufba.br/jacques-ardoino-educacao. Acesso em: 14 maio 2018

McLUHAN, M. Os meios de comunicação como extensão do homem. São Paulo: Cultrix, 1964.

NOVOA, A. Prefácio. In: Josso, M. C. Experiências de vida e treinamento. São Paulo: Cortez, 2004, p. 11-34.

OSÓRIO, E. M. R. (Org.). Bakhtin na prática: leituras do mundo. San Carlos: Pedro e João, 2008 .

PONCE PINEAU, G. A. Auto-treinamento no curso da vida: entre hetero e eco-treinamento. In: Nóvoa, A.; Finger, M. (orgs.). O método biográfico (auto) e treinamento. Lisboa: Ministério da Saúde, 1988, p. 65-77.

SANTAELLA, L. A ecologia pluralista da comunicação: conectividade, mobilidade, onipresença. São Paulo: Paulus, 2010.

SANTOS, E. As imagens e a educação online: convergências entre o cinema e os fóruns de discussão no contexto de uma pesquisa-formação multirreferencial. In: Berino, A.; Soares, S, Conceição. (Orgs.). Educação e imagens: instituições escolares, mídias e contemporaneidade. Rio de Janeiro: DP et Alii, v. 1, p. 105-24, 2010.

SANTOS, E; OKADA, A. A imagem no currículo: da crítica à mídia de massa a ações de autorias dialógicas na prática pedagógica. Revista da FAEEBA - Educação e Contemporaneidade. Salvador, v. 12, n. 20, p. 287-97, jul./dez. 2003.

SPINK, M. J.; BRIGADÃO, J.; NASCIMENTO, V.; CORDEIRO, M. (Org.). A produção de informação em pesquisa social: compartilhando ferramentas. Rio de Janeiro: Edelstein Center for Social Research, 2014 (publicação virtual).

THIOLLENT, M. Metodologia de pesquisa-ação. São Paulo: Cortez Autores Associados, 1986. Disponível em https://marcosfabionuva.files.wordpress.com/2018/08/7-metodologia-dapesquisa-ac3a7c3a3o.pdf. Acesso em: 17 nov. 2018. 
XAVIER, G. M.; CANEN, A. Multiculturalismo e educação inclusiva: contribuições da universidade para a formação continuada de professores de escolas públicas no Rio de Janeiro. Pro-posições, v. 19, n. 3, p. 225-42, set./dez.2008.

\section{Como referenciar este artigo}

AMARAL, Mirian M.; MADDALENA, Tania L.; SANTOS, Edméa O. de. Diversidade cultural, alteridade e vida: o cinema para pensar atos de currículo nos espaçostempos de aprendizagem. Revista Ibero-Americana de Estudos em Educação, Araraquara, v. 15, n. 2, p. 650-666, abr./jun. 2020. e-ISSN: 1982-5587. DOI: https://doi.org/10.21723/riaee.v15i2.12544

Submetido em: 14/05/2019

Revisões requeridas: 20/08/2019

Aprovado em: 24/10/2019

Publicado em: 20/02/2020 


\section{ANEXO1}

Figura 1 - Un Cuento Chino

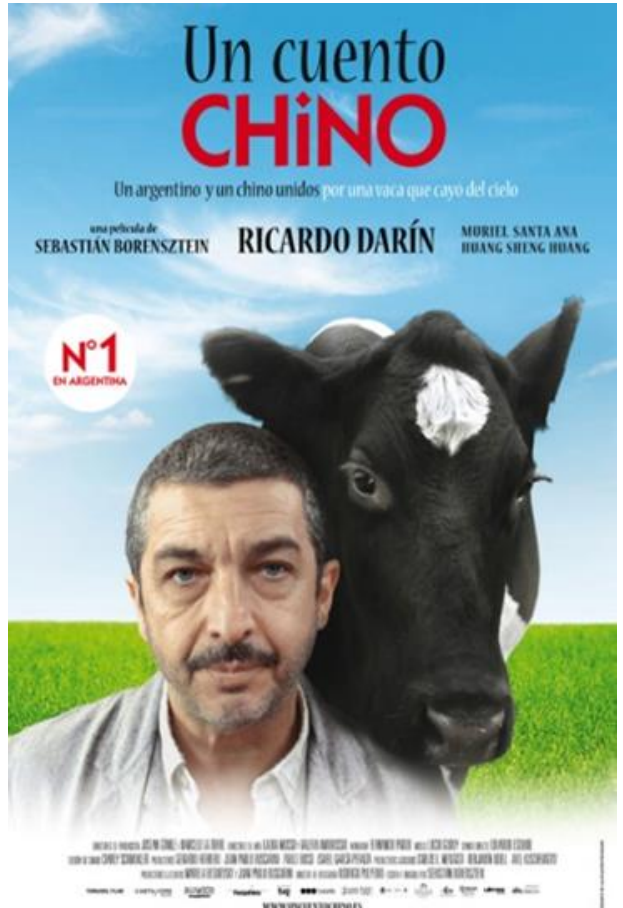

Fonte: http://www.adorocinema.com/filmes/filme-197304/. Acesso em: jan. 2020.

\section{Ficha Técnica}

Data de lançamento: 02 de setembro de 2011 (1h 40min)

Direção: Sebastián Borensztein

Elenco: Ricardo Darín, Ignacio Huang, Muriel Santa Ana, mais

Gênero: Comédia dramática

Nacionalidades: Espanha, Argentina

\section{Sinopse do Filme}

O filme "Um Conto Chinês", dirigido por Sebastián Borensztein, aborda a história de um veterano da Guerra das Malvinas. Roberto é um argentino rabugento, dono de uma loja de ferragens, que se tranca em sua loja, evitando qualquer contato humano. Entretanto, algo extraordinário, singular e inusitado, no local e no momento de sua produção, corta a cena: em um lago na China, o chinês Jun, e sua namorada, trocam alianças de noivado, quando são surpreendidos por uma vaca caindo do céu. $\mathrm{O}$ barco em que estavam virou, e sua namorada morreu. Então, o rapaz decide ir à Argentina procurar um tio. 
Por ironia do destino, Roberto, em um fim de semana, deixa sua vida rotineira, e vai ao cemitério para depositar algumas flores no túmulo de seus pais, e ouvir música em seu carro, perto de uma avenida, quando vê um chinês sendo expulso de um táxi. Corre para ajuda-lo e, por compaixão, leva-o para casa. Impossbilitados de se comunicar, já que Roberto não fala chinês e o chinês não sabe uma palavra de castelhano, a trama gira em torno de resolver essa situação incomum.

Figura 2 - QRCode do trailer oficial do filme

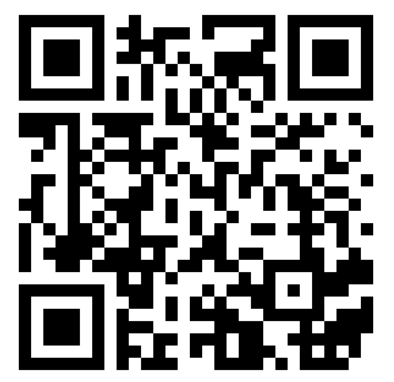

Fonte: http://www.adorocinema.com/filmes/filme-197304/. Acesso em: jan. 2020. 